\title{
Estimation of Costs-Savings and Improved Patient Outcomes of Implementing a Consultation-Liaison Service at Health Sciences North
}

\author{
Elendu Okoronkwo',2 \\ ${ }^{1}$ Kirkwood Site-Health Sciences North, Sudbury, Canada \\ ${ }^{2}$ Northern Ontario School of Medicine, Laurentian University, Sudbury, Canada \\ Email: eokoronkwo@hsnsudbury.ca
}

How to cite this paper: Okoronkwo, E. (2019) Estimation of Costs-Savings and Improved Patient Outcomes of Implementing a Consultation-Liaison Service at Health Sciences North. Open Journal of Psychiatry, 9, 220-234.

https://doi.org/10.4236/ojpsych.2019.93017

Received: April 4, 2019

Accepted: June 23, 2019

Published: June 26, 2019

Copyright $\odot 2019$ by author(s) and Scientific Research Publishing Inc. This work is licensed under the Creative Commons Attribution International License (CC BY 4.0).

http://creativecommons.org/licenses/by/4.0/

\begin{abstract}
Objective: The study was conducted to assess the implementation of a psychiatric consultation-liaison service (C-L) from the perspective of cost-savings, staff satisfaction, patient satisfaction and to assess the general features of patients referred to the C-L service. Methodology: Cost-savings were evaluated using a large cohort of referrals to the hospital were identified using data derived from the Institute of Clinical Evaluative Sciences $(\mathrm{N}=2246)$; these data were divided into pre and post periods with respect to imitation of the C-L service. To evaluate staff satisfaction, 170 nurses and physicians completed an online survey. Patient satisfaction was assessed through a survey assessing various aspects of their experiences with the $\mathrm{C}-\mathrm{L}$ service that was completed by each patient $(\mathrm{N}=40)$. Finally referrals to the $\mathrm{C}-\mathrm{L}$ service $(\mathrm{N}=445)$ were analyzed to discern indicators of the C-L service's efficacy (i.e. reasons for referral, time to accommodate referral). Results: The data indicated: 1 ) a reduction in the number of re-admissions and length of stay after the initiation of the C-L service translating into significant cost-savings for the hospital, 2) that increased staff satisfaction was associated with providing confidence, support, and improved communication, and 3) that the C-L service accommodated approximately $90 \%$ of patients within 1 day. Conclusion: The results of this study support stakeholders' decisions to implement C-L services and also indicate areas of improvement that may improve the quality of C-L services within other institutions.
\end{abstract}

\section{Keywords}

Consultation-Liaison, Psychiatry, Cost-Savings, Staff Satisfaction 


\section{Introduction}

Consultant-liaison (C-L) psychiatry refers to services provided to medically-ill patients within a general hospital setting. As summarized by Hamburg [1], these services may have been readily apparent historically dating back to ancient Chinese, Hindu and Egyptian cultures who considered a fundamental "dis-harmonization" of the body and the mind that was curable by rituals and physical operations. Within a modern day setting, these services have demonstrated efficacy with regards to many descriptors that define cost-savings and overall patient health improvement. In general the tasks of the C-L psychiatrist involve rapid consultation with a patient when prompted by another physician and includes assessment and formulation of general recommendations for psychotropic medications and psychological treatment for follow-up.

According to Gomez [2] approximately $30 \%-65 \%$ of medically-ill patients suffer from a co-morbid mental health problem that adversely affects quality of care, adherence to treatment and cost of services [3]. Studies suggest that up to $34 \%$ of patients suffering from irritable bowel syndrome also have at least one comorbid psychiatric diagnosis [4]. Patients diagnosed with HIV have co-morbid psychiatric diagnosis in more than $48 \%$ of admitted cases [5]. Patients suffering from addictions, in up to $80 \%$ of the cases, also suffer with at least one (and often more) psychiatric co-morbidities [6]. It is estimated that $8 \%$ of the general population suffer from neurological pain and $29 \%-47 \%$ of them have at least one psychiatric co-morbid condition [7]. In patients suffering from COPD, having co-morbid psychiatric disorders results in significantly poorer prognosis and is seen in a large number of COPD patients resulting from the chronic and debilitating nature of the disease [8]. The incidence of psychiatric co-morbidity and cardiac conditions has been increasingly studied as the prevalence continues to be highlighted. In patients suffering from cardiac conditions, depression is common and is associated with the worst outcomes [9]. It is estimated that there has been an increase from $12.9 \%$ to $19 \%$ of patients suffering cardiomyopathies with psychiatric co-morbidities over the 10 year period from 2003-2013 [10]. Therefore, given the extensive list of the relationship between physical and psychological co-morbidities, many hospitals have initiated consultant-liaison psychiatric services that have demonstrated reduced length of stay within the hospital and lower re-admission rates which directly influence the costs associated with hospital operations. As summarized in a systematic review by Wood and Wand [11], there is a large body of empirical evidence suggesting the efficacy of implementation of C-L services within general medicine.

Strategies aimed at optimizing patient outcome while reducing cost and wait times are an ongoing priority at Health Sciences North and throughout the Province of Ontario. The C-L service at this hospital was initiated in March 2014 and is directed at supporting patients admitted for a primary medical concern that have co-morbid psychiatric illness, whether previously diagnosed or not. The service provides primary caregivers the support and psychiatric services necessary to optimize the patients' mental health while they are in hospital receiv- 
ing treatment for their primary health care issue. While the service is currently in its infancy, its growth will include nursing and allied health care support, which will further improve patient care. It is expected that long term costs will also be reduced, since providing this service will: alleviate wait times for the patient; reduce or prevent internal transfers to psychiatric wards; and provide collaborative support for the primary care physician with respect to medication interaction, therapy options and outpatient support. Further, studies find that patients are more likely to continue to seek care and respond to recovery if the therapy is initiated and organized prior to discharge from hospital [12].

Here we present a detailed examination of the clinical and financial outcomes of implementing a C-L service during the first three years of operation. In the series of studies that follow, we aimed to characterize 1) staff and patient satisfaction with regards to their perceptions of the C-L service, 2) demographics and descriptions of patients that have utilized the service, and 3) overall efficacy of the service.

\section{Materials and Methods}

\subsection{Staff/Patient Satisfaction with CL Service}

\subsubsection{Participants}

To discern nurse/physician satisfaction with the consultation liaison service implemented at Health Sciences North, we invited 170 clinicians $(\mathrm{N}=45)$ and nurses $(\mathrm{N}=125)$ from various departments located on the hospital premises to complete a survey accessible online through Survey Monkey. The survey was made available and conducted within the time period of October 2015 and January 2016. The nurses/physicians came from a wide variety of clinical departments including family medicine, critical care, emergency, cardiology, and intensive care. In addition, a total of 40 patients who were referred to the C-L service completed a similar questionnaire.

\subsubsection{Staff and Patient Satisfaction Questionnaire}

We developed a questionnaire to assess the staff satisfaction with the C-L service and created two versions which represented the two general practices: nursing and physician. These items were uploaded to Survey Monkey and a link containing the questionnaire was e-mailed to the nurses and physicians separately. Client satisfaction was similarly assessed using a questionnaire which consisted of items which captured overall patient experiences, their willingness to utilize the C-L service in the future, as well as various aspects of their ongoing treatment after consultation with the C-L service. The responses to both staff and patient questionnaires were imported into Excel where frequencies were tabulated for each of the responses.

\subsection{Clinical Outcomes of the Consult Liaison Service Participants}

Clinical outcomes of the consultation psychiatric service were attempted by 
conducting a chart review. A total of 217 unique records covering 445 referrals $(\mathrm{N}=445)$ were available for the analysis. For each patient seen by the consultation liaison service, two broad streams of information were obtained from 1) the referring physician who disclosed demographic information, the reason for referral, and observed behaviours, and 2) the consultation liaison psychiatrist who collected information regarding when the referral was received/reviewed, diagnostic impressions, medication review, treatment, recommended interventions, patient care management, and follow up plan at discharge. The data was then consolidated at the Psychiatric Outpatient Clinic and entered into an Excel spreadsheet, coded, and entered into SPSS software for descriptive statistical analysis.

\subsection{Effectiveness of the CL Service}

\subsubsection{Participants}

Participants were individuals between the ages of 18 to 59 years of age, admitted to floors of HSN other than psychiatry for a primary condition other than psychiatry or psychological but were discharged within the three years prior to and following the inception of the C-L service within the study period of April 1, 2011 to March 31 2016. Consequently, participants were categorized into two groups: 1) before C-L service initiation, and 2) after C-L service initiation. All data was extracted and summarized by the Institute for Clinical Evaluative Sciences (ICES). Participants were excluded if they were admitted to HSN floors with a primary psychiatric condition or possessed invalid health card numbers.

\subsubsection{Data Extraction}

Based on the inclusion and exclusion criteria, the last discharge date of the first episode of care was kept for each person. Using the Registered Persons Database (RPDB) data, baseline characteristics (e.g., age, sex, income quintile, etc.) of the cohort were determined. Using the Discharge Abstract Database (DAD), hospitalization data such as average length of stay and readmissions were pulled for the cohort. To determine Emergency Department visits, the National Ambulatory Care Reporting System (NACRS) data was utilized. When extracting data from NACRS, comorbid psychiatric or psychological illness was defined as having a psychiatric or psychological illness in "other" dx10codes (2-10) whereas primary psychiatric or psychological medical conerns were defined as having psychiatric or psychological illness as the "main" dx10code (1). Using the cohort, the Ontario Health Insurance Plan (OHIP) billing was extracted to determine the frequency of outpatient billing/visits during the pre and post time frames. To identify patient transfers from hospitalization to mental health beds the last date of each patient's hospitalization record was kept. The key number of the last hospitalization per patient was then linked to Ontario Mental Health Reporting System (OMHRS) to identify if a matching record with the same patient information and subsequent admission date existed. Similarly, to identify patient transfers from mental health beds to hospitalization, OMHRS data was pulled for the cohort. The key number from the last mental health bed date per 
person was then linked to DAD to identify if a patient transfer existed.

\subsubsection{Data Analysis}

All data was pooled and separated into the two groups representing the pre and post-periods of the initiation of the CL service at HSN. Data was then summarized using descriptive statistics (frequency, mean, standard deviation) for the following measures: 1) hospital length of stay, hospital readmissions for both the total period as well as 6 months following the last discharge, patient transfers, emergency department visits, number of outpatient visits with general practitioners/family physicians as well as psychiatrists. These data, particularly the length of stay, formed the basis for calculating an estimated cost-savings of implementing the C-L service.

All ethical clearance for each study was approved by the Health Sciences North Research Ethics Board.

\section{Results}

\subsection{Staff/Physician Satisfaction}

There were a total of 170 respondents to the satisfaction questionnaire which included 125 registered and practical nurses as well as 45 physicians. Preliminary one-way analyses of variance on individual items assessing the quality and effectiveness of the CL service indicated that there were no mean differences in how nurses and physicians responded to the items $(\mathrm{p}>0.05)$. Therefore all data was pooled into a single database. A summary of responses to the set of core items assessing the quality and effectiveness of the survey as rated by both the physicians and nursing staff is presented in Table 1.

An exploratory stepwise multiple regression analysis was performed to predict overall satisfaction of the CL service from the discrete survey items assessing various indices of CL service performance as viewed by the physician and nursing staff. Consequently all data was translated along a ratio scale by dividing the responses to the items by the total number of options for each item minus 1; for example the response "Quite dissatisfied" on item 15 would be 0 and very satisfied would be $3 / 3$, or 1 . The analysis demonstrated a significant relationship (Multiple $\mathrm{R}=0.904$, Adjusted $\mathrm{R}^{2}=0.808$ ) between overall satisfaction which could be predicted by three general constructs listed in decreasing importance as inferred by the beta standardized coefficient: 1) the ability for the CL service to help physicians and nurses treat their patients more effectively, 2) the ability for the CL service to endow confidence with addressing mental health, and 3) the verbal quality of the CL service. The B and standardized beta coefficients are listed in Table 2.

A total of 40 patients completed the satisfaction questionnaire at the end of their consultation with the C-L service. A summary of their responses of selected items within the questionnaire are shown in Table 3. According to the data, $67.5 \%$ reported that they would take advantage of the C-L service if they were admitted to the hospital once more. In addition, an overall positive rating was 
received by the C-L service where $65 \%$ of patients reported that the care they received was very good and $60 \%$ indicated that their recovery was improved through participation in the C-L service.

Table 1. Detailed response rates for various items on the Staff/Physician Satisfaction Questionnaire.

\begin{tabular}{|c|c|c|c|}
\hline Item & Option & $\begin{array}{l}\text { Number of } \\
\text { Endorsed } \\
\text { Responses (\%) }\end{array}$ & $\mathbf{N}$ \\
\hline \multirow{4}{*}{$\begin{array}{l}\text { How quickly did a psychiatrist } \\
\text { see your patient? }\end{array}$} & Within 24 hours & 35.1 & \multirow{4}{*}{77} \\
\hline & Within 48 hours & 33.8 & \\
\hline & Within 72 hours & 13.0 & \\
\hline & It took longer than 72 hours & 18.2 & \\
\hline \multirow{4}{*}{$\begin{array}{l}\text { Did the CL Service psychiatrist } \\
\text { understand the core question } \\
\text { being asked? }\end{array}$} & Always & 23.1 & \multirow{4}{*}{78} \\
\hline & Usually & 52.6 & \\
\hline & Sometimes & 23.1 & \\
\hline & Never & 1.3 & \\
\hline \multirow{5}{*}{$\begin{array}{l}\text { How would you rate the quality } \\
\text { of verbal communication with } \\
\text { the medical team in addition to } \\
\text { charting patient record? }\end{array}$} & Excellent & 12.2 & \multirow{5}{*}{74} \\
\hline & Good & 28.4 & \\
\hline & Satisfactory & 21.6 & \\
\hline & Fair & 25.7 & \\
\hline & Poor & 12.2 & \\
\hline \multirow{5}{*}{$\begin{array}{l}\text { Did the CL service psychiatrist } \\
\text { offer practical and insightful } \\
\text { medication choices for your } \\
\text { patient? }\end{array}$} & Always & 13.5 & \multirow{5}{*}{74} \\
\hline & Usually & 37.8 & \\
\hline & Sometimes & 39.2 & \\
\hline & Never & 4.1 & \\
\hline & Medications were not ordered & 5.4 & \\
\hline \multirow{5}{*}{$\begin{array}{l}\text { Did the CL service psychiatrist } \\
\text { quickly manage the patient's } \\
\text { behavioural problems? }\end{array}$} & Always & 5.4 & \multirow{5}{*}{74} \\
\hline & Usually & 32.4 & \\
\hline & Sometimes & 51.4 & \\
\hline & Never & 5.4 & \\
\hline & Not applicable & 5.4 & \\
\hline \multirow{4}{*}{$\begin{array}{l}\text { Did the CL service psychiatrist } \\
\text { provide outpatient follow-up or } \\
\text { referral to outpatient counseling } \\
\text { management services? }\end{array}$} & Always & 13.5 & \multirow{4}{*}{74} \\
\hline & Usually & 31.1 & \\
\hline & Sometimes & 43.2 & \\
\hline & Not applicable & 12.2 & \\
\hline \multirow{4}{*}{$\begin{array}{l}\text { Did the CL service psychiatrist } \\
\text { improve your confidence in } \\
\text { addressing mental health issues } \\
\text { with your patient? }\end{array}$} & Yes, they helped a great deal & 21.1 & \multirow{4}{*}{76} \\
\hline & Yes, they helped somewhat & 43.4 & \\
\hline & No, they didn't really help & 32.9 & \\
\hline & No, they seemed to make things worse & 2.6 & \\
\hline
\end{tabular}




\section{Continued}

\begin{tabular}{|c|c|c|c|}
\hline \multirow{4}{*}{$\begin{array}{l}\text { Has the CL service helped } \\
\text { you treat your patients } \\
\text { more effectively? }\end{array}$} & Always & 15.6 & \multirow{4}{*}{77} \\
\hline & Usually & 31.2 & \\
\hline & Sometimes & 44.2 & \\
\hline & Never & 9.1 & \\
\hline \multirow{4}{*}{$\begin{array}{l}\text { Are you more confident in } \\
\text { treating patients with psychiatric } \\
\text { co-morbidities knowing the CL } \\
\text { service is available to support you? }\end{array}$} & Always & 23.7 & \multirow{4}{*}{76} \\
\hline & Usually & 21.1 & \\
\hline & Sometimes & 38.2 & \\
\hline & Never & 17.1 & \\
\hline \multirow{4}{*}{$\begin{array}{l}\text { Overall, how satisfied are you } \\
\text { with the CL service? }\end{array}$} & Very satisfied & 22.4 & \multirow{4}{*}{76} \\
\hline & Somewhat satisfied & 30.3 & \\
\hline & Indifferent or mildly satisfied & 25.0 & \\
\hline & Quite dissatisfied & 22.4 & \\
\hline
\end{tabular}

Table 2. Results of the stepwise multiple regression for predicting overall service satisfaction from various items on the Staff Satisfaction Survey. Higher levels of satisfaction were associated with increases in 1) helping staff treat their patients more effectively, 2) improving the confidence in staff of addressing mental health and 3) increased verbal communication with the staff and physicians.

\begin{tabular}{llllll}
\hline Item & B & Standard Error & Beta & t & Sig. \\
\hline Constant & -0.155 & 0.052 & & -2.975 & 0.004 \\
$\begin{array}{l}\text { Did the CL service help you treat patients } \\
\text { more effectively? }\end{array}$ & 0.515 & 0.102 & 0.439 & $5.051<0.001$ \\
$\begin{array}{l}\text { Did the CL service improve your } \\
\text { confidence in addressing mental health }\end{array}$ & 0.466 & 0.116 & 0.341 & 4.018 & $<0.001$ \\
$\begin{array}{l}\text { How would you rate the quality of verbal } \\
\text { communication? }\end{array}$ & 0.26 & 0.097 & & & \\
\end{tabular}

Table 3. Detailed reponses for selected items from the Patient Satisfaction Questionnaire administered to assess patients' experiences with the C-L Service.

\begin{tabular}{|c|c|c|c|c|c|c|c|}
\hline \multirow{2}{*}{ Question } & \multirow{2}{*}{$\begin{array}{l}\text { Response } \\
1\end{array}$} & \multirow{2}{*}{$\begin{array}{l}\text { Response } \\
2\end{array}$} & \multirow{2}{*}{$\begin{array}{l}\text { Response } \\
3\end{array}$} & \multirow{2}{*}{$\begin{array}{l}\text { Response } \\
4\end{array}$} & \multirow{2}{*}{$\begin{array}{l}\text { Response } \\
5\end{array}$} & \multicolumn{2}{|c|}{ Response No } \\
\hline & & & & & & 6 & Response (\%) \\
\hline $\begin{array}{l}\text { How soon after you were admitted } \\
\text { to HSN did your physician refer } \\
\text { you to see a psychiatrist? }\end{array}$ & $\begin{array}{l}\text { Within } 24 \\
\text { hours }(35 \%)\end{array}$ & $\begin{array}{l}\text { Between } 1-2 \\
\text { days }(5 \%)\end{array}$ & $\begin{array}{l}\text { Between } 2 \text { - } 3 \\
\text { days }(2.5 \%)\end{array}$ & $\begin{array}{l}\text { More than } 3 \\
\text { days }(27 \%)\end{array}$ & $\begin{array}{l}\text { Unknown } \\
(30 \%)\end{array}$ & & \\
\hline $\begin{array}{l}\text { How long did it take the } \\
\text { psychiatrist to consult with you? }\end{array}$ & $\begin{array}{l}\text { Within } 24 \\
\text { hours }(27.5 \%)\end{array}$ & $\begin{array}{l}\text { Between } 1-2 \\
\text { days }(15 \%)\end{array}$ & $\begin{array}{l}\text { Between } 2 \text { - } 3 \\
\text { days }(5 \%)\end{array}$ & $\begin{array}{l}\text { More than } 3 \\
\text { days }(25 \%)\end{array}$ & $\begin{array}{l}\text { Unknown } \\
(27.5 \%)\end{array}$ & & \\
\hline $\begin{array}{l}\text { How many times were you visited } \\
\text { by a member of the Psychiatry C-L } \\
\text { service? }\end{array}$ & Once $(77.5 \%)$ & $\begin{array}{l}\text { Every few } \\
\text { days }(22.5 \%)\end{array}$ & Daily (0\%) & $\begin{array}{l}\text { Twice daily } \\
(0 \%)\end{array}$ & & & \\
\hline $\begin{array}{l}\text { Did your discharge plan include a } \\
\text { scheduled appointment at the } \\
\text { psychiatrist' office? }\end{array}$ & Yes (17.5\%) & No $(67.5 \%)$ & $\begin{array}{l}\text { I was told to } \\
\text { call to } \\
\text { arrange an } \\
\text { appointment } \\
(5 \%)\end{array}$ & $\begin{array}{l}\text { Unknown } \\
(7.5 \%)\end{array}$ & & & \\
\hline
\end{tabular}




\section{Continued}

Have you been under the care of a mental health professional in the past?

\begin{tabular}{|c|c|c|}
\hline Never (30\%) & $\begin{array}{l}\text { Sometimes } \\
(52.5 \%)\end{array}$ & Usually \\
\hline $\begin{array}{l}\text { Improved: left } \\
\text { the hospital } \\
\text { with a more } \\
\text { positive } \\
\text { outlook }(62.5 \%)\end{array}$ & $\begin{array}{l}\text { Reduced: left } \\
\text { the hospital } \\
\text { with a more } \\
\text { negative } \\
\text { outlook }(0 \%)\end{array}$ & $\begin{array}{l}\text { Had no } \\
\text { change } \\
(37.5 \%)\end{array}$ \\
\hline
\end{tabular}

Are you involved as much as you want in decisions about your mental health treatment?

\section{Never}

$(32.5 \%)$

Do you understand your

mental health care plan?

Not at all

$(12.5 \%)$

Did your C-L psychiatrist clearly Not at all explain the purpose of medication? (17.5\%)

Did the C-L staff clearly explain possible medication side effects?

Were you individual needs, preferences and values respected in Never (7.5\%) your treatment by the $\mathrm{C}-\mathrm{L}$ service?

Do you feel that you are treated with respect by C-L staff?

Do you feel that enough consideration is given to any physical problems that you have (for example; diabetes, weight gain, Never (10\%) heart disease) in your mental health treatment?
Sometimes

$(0 \%)$

Usually

$(12.5 \%)$

Always

$(52.5 \%)$

Not Applicable: no mental halth treatment at this time $(2.5 \%)$

Not Applicable $(10 \%)$

$10 \%$

I have not been prescribed medication (32.5\%)

I have not been

Sometimes (0\%)

Usually (0\%) Always (20\%) prescribed medication (35\%)

Sometimes

Usually (5\%) Always (80\%)

$2.50 \%$

Sometimes Usually

(0\%) $\quad(2.5 \%)$

Always (95\%)

Sometimes

(5\%)

$\begin{array}{ll}\text { Usually (0\%) } & \begin{array}{l}\text { Always } \\ (77.5 \%)\end{array}\end{array}$

I do not have any physucal health problems (5\%)
$2.50 \%$

\subsection{Clinical Demographics and Outcomes of the CL Service}

\subsubsection{Time to CL Service and Total Number of Visits}

Approximately 71 percent of all cases referred to the Psychiatric Consult Liaison Service were accommodated on the same day as the date of referral. The data indicated $94 \%$ of the cases were accommodated within one day. Figure 1(a) displays a histogram of the available data. The majority of patients had one visit $(\sim 83 \%)$ with a psychiatrist during their participation in the Consultation Liaison Service (Figure 1(b)).

\subsubsection{Focus of Consultation}

A total of 445 records were available with details regarding the focus of consultation with a psychiatrist. The results indicated the following in order of decreasing percentage of cases (in parentheses): medication review/treatment options (19.8\%), psychiatric diagnosis \& medication review / treatment options (19.1\%), 
suicide risk assessment (18\%), medication review/treatment options \& patient care management $(14.6 \%)$, patient care management only $(11.7 \%)$, psychiatric diagnosis only $(9.2 \%)$, psychiatric diagnosis \& patient care $(4.94 \%)$, medication review/treatment $(2.7 \%)$.

\subsubsection{Affected Organ Systems, Diagnoses, and Outcome at Discharge}

Descriptive statistics were computed for data consisting of the organ system that was affected by the patient; this data was available for a smaller sample $(\mathrm{N}=53)$. Figure 2(a) indicates that the highest number of referrals affected both the cardiovascular and respiratory systems, which represented a cumulative percentage of about $45 \%$ of the total organ systems A preliminary analysis was conducted to discern the distribution of medical diagnoses amongst patients referred to the CL service. Figure 2(b) indicates that the majority ( 26\%) of cases referred to the service presented because of an overdose. When the data were coded accordingly, analyses demonstrated that the primary outcome for patients of the CL service was Psychiatric Outpatient Clinic (POC) follow-up; these results are summarized in Figure 2(c).

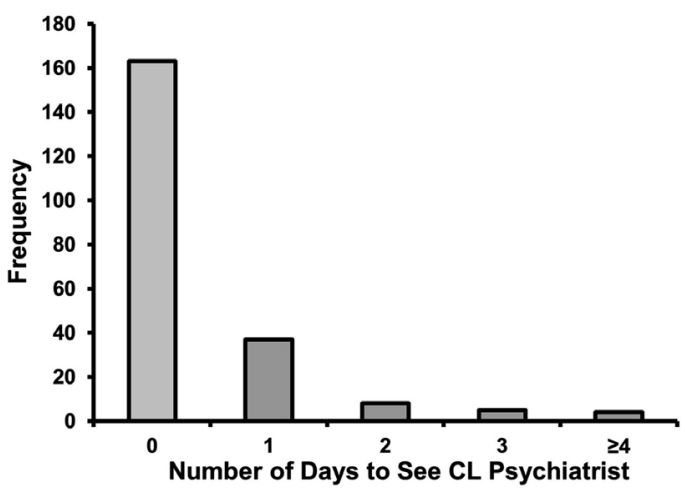

(a)

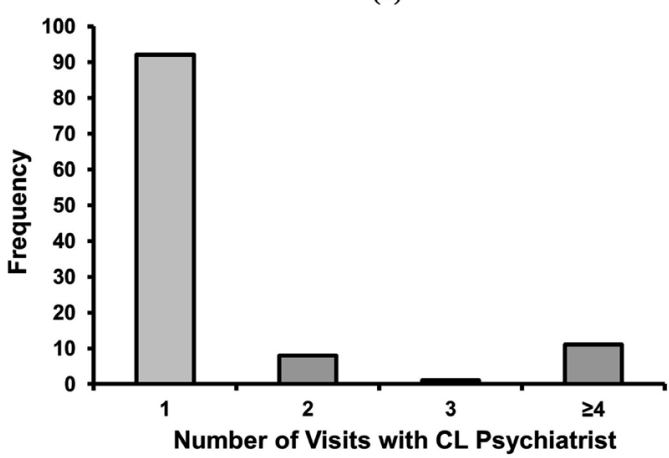

(b)

Figure 1. (a) Histogram depicting the total numbers of patients who were seen within 0 to $\geq 4$ days after the initial referral to the CL psychiatrist. The majority were seen on the same day as the referral. (b) Histogram showing the numbers of patients who saw a psychiatrist, 1, 2, 3 and $\geq 4$ times during their enrolment in the CL psychiatric service. 


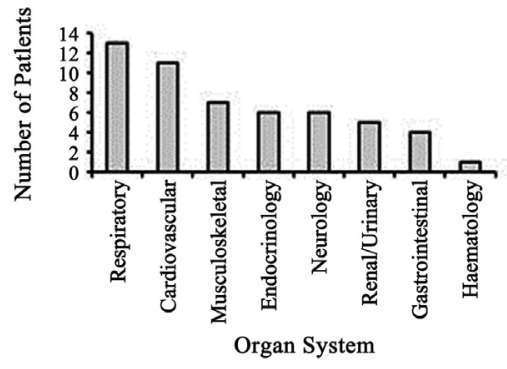

(a)

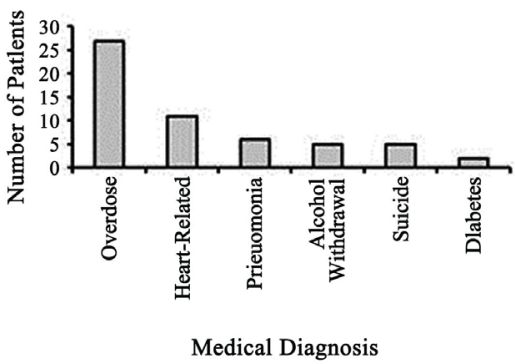

(b)

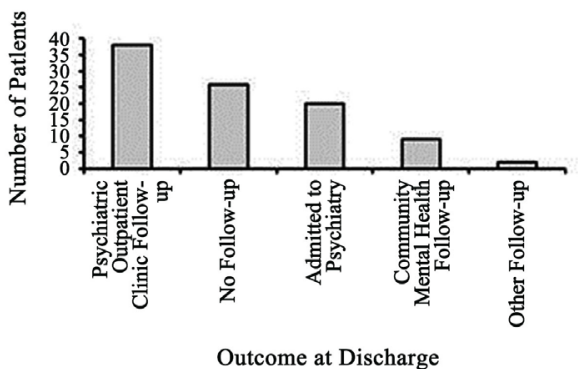

(c)

Figure 2. (a) Histogram showing the frequencies of CL service referrals organized as a function of organ system. The collective majority of cases referred from Respiratory and Cardiovascular (b) Histogram showing the reasons for referral. About $50 \%$ of cases were referred to the CL service for reasons of substance overdose. (c) Distributions of the outcome at discharge following a visitation by the CL service psychiatrist.

\subsection{Efficacy of the CL Service}

\subsubsection{Baseline Descriptives}

During the study period (April 1, 2011 to March 31, 2016) a total of 2246 referrals were admitted to floors of Health Sciences North (HSN) for reasons other than psychiatric or psychological; there were 1267 and 979 referrals before and after the initiation of the $\mathrm{C}-\mathrm{L}$ service respectively. The average age of individuals identified in the cohort were similar pre (Mean $=42.36, \mathrm{SD}=12.35)$ and post $($ Mean $=41.03, \mathrm{SD}-12.54)$ initialization of the C-L service; male (Pre $=50.2 \%$, Post $=49.8 \%)$ and female (Pre $=50.46 \%$, Post $=49.54 \%)$ proportions were also conserved between the two periods.

\subsubsection{Readmission Rates and Length of Stay}

The total numbers of hospital re-admissions both before and after the initiation of the CL service were 412 and 231, respectively. When the total sample sizes for the two groups was considered, the percentage of re-admissions to hospitals for both groups were $33 \%$ and $24 \%$ for the pre and post periods. This data indicated that there was about a $10 \%$ decrease in the number of hospitalizations following the introduction of the CL Psychiatric Service at HSN (Figure 3). The average length of stay before and after the initiation of the C-L service was 9.24 days (SD $=35.10)$ and 7.25 days $(\mathrm{SD}=16.88)$ days respectively (Figure 3 ).

\section{Discussion}

In this paper, a detailed examination of initiating a consultant-liaison psychiatric 


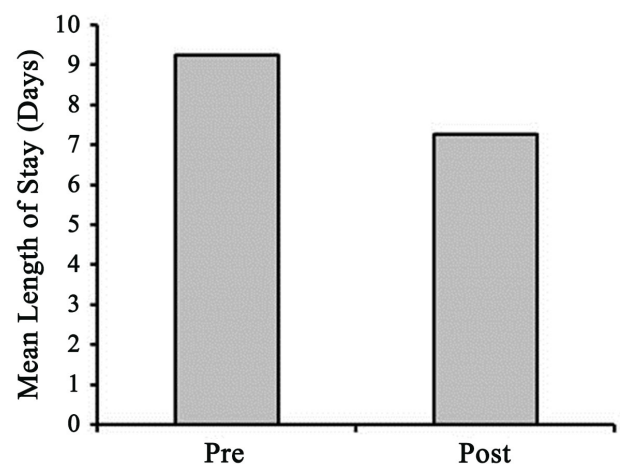

Figure 3. Differences average length of stay before and after the initiation of the C-L service. The average length of stay decreased by 1.99 days. Error bars represent standard error of the mean.

service in a rural hospital setting was fully examined from the perspectives of staff, patients as well as within a cost-saving context within the first three years of its operation. Consultation-liaison services have been demonstrated to be an effective means of increasing the quality of healthcare around the world and evidence-based assessment of their efficacy have largely indicated that their implementation can help to reduce costs when considered as an option during the treatment of medical conditions whose primary focus is general medicine. While the design of the study is primarily correlative, there are a myriad of congruencies between the findings of this study and the results of similar studies conducted at different institutions indicating a potential generalizability of the empirical evidence supporting psychiatric consultation-liaison initiatives. The methodologies utilized in this examination are commensurate with previous audits [13] [14].

Survey data collected from staff and physicians indicated that satisfaction was largely a function of 1) helping staff treat their patients more effectively, 2) improving the confidence in staff for addressing mental health issues, and 3) increased verbal communication between the C-L psychiatrist and the staff and physicians of other departments; the linear combination of these three factors accounted for about $81 \%$ of the variance in satisfaction. These results suggest that the C-L service may extend its benefits outside of the putative doctor-to-patient care and may have secondary benefits that serve to support physicians and staff who may have limited training in treating individuals with co-morbid psychiatric conditions.

An investigation of the patient satisfaction was assessed using a questionnaire which queried various aspects of their experiences with the C-L service. Overall, favourable reviews were reported with respect to the patients' willingness to consult with the C-L service in the future, their positive overall rating of the service, and their overall recovery. Interestingly, a larger proportion of the patients indicated that their own values, preferences and individual needs were respected (80\% of respondents) during their consult and $95 \%$ of respondents indicated that they felt that they were treated with respect by the C-L staff. 
It is well-known that depression is a significant psychiatric co-morbidity amongst populations with diverse medical illnesses and has been observed in patients with primary medical diagnosis of type I (12\%) and type II (17.6\%) diabetes mellitus, chronic obstructive pulmonary disease (42\% - 57\%), myocardial infarction (19.8\%), closed head injury (42\%) [15] [16] [17] [18] [19]. While primary psychiatric diagnoses were not considered in this manuscript, the data indicated that suicide risk assessment accounted for about $18 \%$ of the reasons for referral to the $\mathrm{C}-\mathrm{L}$ service which matches the approximate figure published by Huyse et al. [20] who reported that deliberate self-harm accounted for about $17 \%$ of the referrals which was representative of a European population $(\mathrm{N}=$ 14,717) derived from 11 countries treated by 56 participating C-L services.

We evaluated the efficacy of the service using a cohort of patients pre/post the initiation of the C-L service. In this analysis the main objective was to evaluate the numbers of individuals who are re-admitted for psychiatric reasons after being discharged from the hospital with a medical diagnosis other than psychiatric. The analysis indicated that the C-L service was associated with about a $10 \%$ decrease in re-admissions when accommodating for the sample sizes of both pre and post cohorts. According to the data published by the Canadian Institute for Health Information [21], the average year length of stay for inpatient hospitalizations in Ontario between 2010 to 2017 was 6.64 days ( $S D=0.11$ ). In a recent report [22], they estimated mean cost of a standard hospital stay ( $\$ /$ weighted case) using 4 methods that accommodate 1) simple summation of inpatient-related expenses, 2) pro rata per diem allocation, 3) adjustment based upon differences in databases which produce the estimates, and 4) adjustment of patient stays greater than 365 days. The average cost across all four methods was $\$ 6000.80$ ( $S D=381.86$ ) for fiscal years 2009-2014. Using this data an estimate of the cost of inpatient hospitalization per day was calculated by dividing the average total cost per stay by the average length of stay and was estimated to be $\$ 903.73 /$ day for each inpatient. The cost-savings can then be calculated based upon difference in length of stay pre/post the initiation of the C-L service (9.24 days -7.25 days $=1.99$ days). Multiplication of the cost/day per inpatient by 1.99 days results in a savings of approximately $\$ 1798$ per inpatient. When expressed as cost-savings per 100 patients, the amount would be $\$ 179,800$.

Examination of the chart data indicated that $90 \%$ of consultations performed by the C-L psychiatrist were accommodated within 1 day and meets the guidelines outlined by Archinard et al. [23] and O'Keefe et al. [24]. This figure is important when examined within the context of Sockalingam [25] et al. were the first to indicate a positive relationship between time-to-referral of a C-L service and resulting length of stay within the hospital with an overall correlation of 0.77 between the two measures. This relationship effectively indicates that length of stay within the hospital increases as a function of the amount of time for the C-L psychiatrist to provide services to the patient. The results of our analysis provide further support for their findings. Specifically, we observed a reduction in the length of stay of approximately 2 days after the initiation of the C-L service. 
Perhaps interestingly, there was disconcordance between the perceptions of the staff/physician's reported time to consultation and those indicated by the chart histories of the patient. Whereas the chart histories indicated that about $90 \%$ of consultations were accommodated within 1 day, only about $33 \%$ of staff and physicians (Table 1) reported consultation within the same temporal period. This discrepancy could be an artifact of memory. Nursing staff and physicians see between 10 - 100 patients per day which may prove difficult to track individual cases for accurate reporting during the survey. Alternatively, it may be a logistics error whereby physicians/nurses are not informed (through electronic transfer of consultation dates) that the psychiatrist has already seen the patient and thus the feedback is not provided for an accurate assessment. In either case, the results of this discrepancy may indicate that greater care be taken to report consultations that have been performed so that physicians/nurses can maintain confidence in referring future patients.

\section{Conclusion}

The findings presented in this correlative study support the works of others demonstrating the efficacy and cost-savings of implementing consultation liaison psychiatric services from multiple perspectives. Initiation of a C-L service within a rural hospital in Northern Ontario, Canada was associated with lower readmission rates and a decreased length of stay which was estimated to incur significant cost-savings. Future considerations for evaluating the efficacy of the current program in the future may include punctate examination of these figures in concert with nurse/physician feedback to promote a greater quality of care to patients with primarily medical diagnoses [26]. This study also highlights the need to improve communication between physicians/nurses and C-L staff. Perhaps more robust differences would have been demonstrated if the C-L service was well staffed and had sufficient resources (i.e. social workers, occupational therapists, psychologists) that are comparable to other well-established C-L services in hospitals.

\section{Acknowledgements}

This work was supported by a grant issued by the Northern Ontario Academic Medical Association (NOAMA) and had no role in the design of the study; collection, analysis and interpretation of the data; writing the manuscript; or in the decision to submit the article for publication.

This study made use of de-identified data from the ICES Data Repository, which is managed by the Institute for Clinical Evaluative Sciences with support from its funders and partners: Canada's Strategy for Patient-Oriented Research (SPOR), the Ontario SPOR Support Unit, the Canadian Institutes of Health Research and the Government of Ontario. The opinions, results and conclusions reported are those of the authors. No endorsement by ICES or any of its funders or partners is intended or should be inferred. 
Parts of this material are based on data and information provided by Cancer Care Ontario (CCO). The opinions, results, view, and conclusions reported in this paper are those of the authors and do not necessarily reflect those of CCO. No endorsement by CCO is intended or should be inferred.

These datasets were linked using unique encoded identifiers and analyzed at the Institute for Clinical Evaluative Sciences (ICES).

\section{Conflicts of Interest}

The author declares no conflicts of interest regarding the publication of this paper.

\section{References}

[1] Hamburg, B.A. (1987) Consultation/Liaison Psychiatry. Bulletin of the New York Academy of Medicine, 63, 376-385.

[2] Gomez, J. (1987) Liaison Psychiatry: Mental Health Problems in the General Hospital. Croom-Helm, London.

[3] Parsonage, M. and Fossey, M. (2011) Economic Evaluation of a Liaison Psychiatry Service. Centre for Mental Health, London.

[4] Sertbas, Y., Belli, H., Piskinpasa, N., Ural, C., Akbudak, M., Sertbas, M. and Oncu, F. (2012) Assessment of Psychiatric Symptoms and Co-Morbidities in Patients with Irritable Bowel Syndrome. West Indian Medical Journal, 61, 544-548.

https://doi.org/10.7727/wimj.2012.166

[5] Sullivan, A., et al. (2012) Increase in HIV Drug Resistance among Treatment; Naive Patients in Ontario, Canada, 2005-2011. Public Health Agency of Canada, Montrea.

[6] Marta Torrens, P.C.-R.-S. and Bulbena, A. (2012) Psychiatric Co-Morbidity and Substance Use Disorders: Treatment in Parallel Systems or in One Integrated System? Substance Use and Misuse, 47, 1005-1014. https://doi.org/10.3109/10826084.2012.663296

[7] Radat, F., Margot-Duclot, A. and Attal, N. (2013) Psychiatric Co-Morbidities in Patients with Chronic Peripheral Neuropathic Pain: A Multicentre Cohort Study. European Journal of Pain, 17, 1547-1557. https://doi.org/10.1002/j.1532-2149.2013.00334.x

[8] JR Mehta, I.R. (2014) Association of Psychiatric Co-Morbidities and Quality of Life with Severity of Chronic Obstructive Pulmonary Disease. East Asian Archives of Psychiatry, 24, 148-155.

[9] Grady, K.L., et al. (2000) Team Management of Patients with Heart Failure: A Statement for Healthcare Professionals from the Cardiovascular Nursing Council of the American Heart Association. Circulation, 102, 2443-2456. https://doi.org/10.1161/01.CIR.102.19.2443

[10] Teo, R., et al. (2014) The Burden and Trends of Psychiatric Co-Morbidities amongst Patients with Cardiomyopathy. International Journal of Cardiology, 174, 398-399.

[11] Wood, R. and Wand, A.P. (2014) The Effectiveness of Consultation-Liaison Psychiatry in the General Hospital Setting: A Systematic Review. Journal of Psychosomatic Research, 76, 175-192. https://doi.org/10.1016/j.jpsychores.2014.01.002

[12] Alper, E., O’Malley, T. and Greenwald, J. (2014) Hospital Discharge and Readmission. UpToDate.

[13] Lyne, J., Hill, M., Burke, P. and Ryan, M. (2009) Audit of an Inpatient Liaison Psy- 
chiatry Consultation Service. International Journal of Health Care Quality Assurance, 22, 278-288. https://doi.org/10.1108/09526860910953548

[14] Snyder, S., Strauss, E., Burton, R., Nuber, G., Abernathy, T., MA, H.S., Sacks, C., et al. (1991) Cost Offset from a Psychiatric Consultation-Liaison Intervention with Elderly Hip Fracture Patients. American Journal of Psychiatry, 148, 1044-1049. https://doi.org/10.1176/ajp.148.8.1044

[15] Barnard, K.D., Skinner, T.C. and Peveler, R. (2006) The Prevalence of Co-Morbid Depression in Adults with Type 1 Diabetes: Systematic Literature Review. Diabetic Medicine, 23, 445-448. https://doi.org/10.1111/j.1464-5491.2006.01814.x

[16] Ali, S., Stone, M.A., Peters, J.L., Davies, M.J. and Khunti, K. (2006) The Prevalence of Co-Morbid Depression in Adults with Type 2 Diabetes: A Systematic Review and Meta-Analysis. Diabetic Medicine, 23, 1165-1173. https://doi.org/10.1111/j.1464-5491.2006.01943.x

[17] Mikkelsen, R.L., Middelboe, T., Pisinger, C., et al. (2004) Anxiety and Depression in Patients with Chronic Obstructive Pulmonary Disease (COPD): A Review. Nordic Journal of Psychiatry, 58, 65-70. https://doi.org/10.1080/08039480310000824

[18] Thombs, B.D., Bass, E.B., Ford, D.E., Stewart, K.J., Tsilidis, K.K., Patel, U., Ziegelstein, R.C., et al. (2006) Prevalence of Depression in Survivors of Acute Myocardial Infarction. Journal of General Internal Medicine, 21, 30-38. https://doi.org/10.1111/j.1525-1497.2005.00269.x

[19] Kreutzer, J.S., Seel, R.T. and Gourley, E. (2001) The Prevalence and Symptom Rates of Depression after Traumatic Brain Injury: A Comprehensive Examination. Brain Injury, 15, 563-576. https://doi.org/10.1080/02699050010009108

[20] Huyse, F.J., Herzog, T., Lobo, A., Malt, U.F., Opmeer, B.C., Stein, B., Cardoso, G., et al. (2001) Consultation-Liaison Psychiatric Service Delivery: Results from a European Study. General Hospital Psychiatry, 23, 124-132.

https://doi.org/10.1016/S0163-8343(01)00139-6

[21] Canadian Institute for Health Information. https://apps.cihi.ca/mstrapp/asp/Main.aspx

[22] Canadian Institute for Health Information (2017) Understanding Variability in the Cost of a Standard Hospital Stay. CIHI, Ottawa.

[23] Archinard, M., Dumont, P. and De Tonnac, N. (2005) Guidelines and Evaluation: Improving the Quality of Consultation-Liaison Psychiatry. Psychosomatics, 46, 425-430. https://doi.org/10.1176/appi.psy.46.5.425

[24] O’Keeffe, N., Ramaiah, U.S., Nomani, E., Fitzpatrick, M. and Ranjith, G. (2007) Benchmarking a Liaison Psychiatry Service: A Prospective 6-Month Study of Quality Indicators. Psychiatric Bulletin, 31, 345-347.

https://doi.org/10.1192/pb.bp.107.014837

[25] Sockalingam, S., Alzahrani, A., Meaney, C., Styra, R., Tan, A., Hawa, R. and Abbey, S.E. (2016) Time to Consultation-Liaison Psychiatry Service Referral as a Predictor of Length of Stay. Psychosomatics, 57, 264-272. https://doi.org/10.1016/j.psym.2016.01.005

[26] Lavakumar, M., Gastelum, E.D., Hussain, F., Levenson, J., Wharton, R.N., Muskin, P.R. and Shapiro, P.A. (2013) How Do You Know Your Consult Service Is Doing a Good Job? Generating Performance Measures for CL Service Effectiveness. Psychosomatics, 54, 567-574. https://doi.org/10.1016/j.psym.2013.03.001 